\title{
Bradycardia in Children During General Anaesthesia
}

\author{
Judith A. Lens ${ }^{1}$, Jeroen Hermanides ${ }^{1}$, Peter L. Houweling ${ }^{1}$, \\ Jasper J. Quak² and David R. Colnot ${ }^{2}$ \\ ${ }^{1}$ Diakonessenhuis Utrecht, Departments of Anaesthesiology \\ ${ }^{2}$ Otolaryngology/Head and Neck Surgery \\ The Netherlands
}

\section{Introduction}

Bradycardia in association with anaesthesia may lead to insufficient cardiac output and decreased delivery of oxygen to vital organs. In children the heart rate is the dominant factor for cardiac output, since the developing heart is less compliant and contractile and stroke volume cannot increase much. Thus, when bradycardia occurs in children during anaesthesia, cardiac output falls and may lead to serious cardiac arrhythmias and even cardiac arrest. In this chapter, the incidence, causes and risk factors, as well as the consequences and possible treatment of bradycardia in children during general anaesthesia are described and discussed. A focus is made on the incidence and causes of bradycardia in children undergoing adenotonsillectomy under general anaesthesia.

\section{Bradycardia and general anaesthesia in children}

\subsection{Physiology}

The normal heart rate decreases with increasing age in children (Figure 1). Therefore, a heart rate less then 100 beats per minute in very young children is a bradycardia by definition. For children 3 years of age, this means a heart rate less then 65 beats per minute. In the first months after birth, the risk for bradycardia is even higher as a result of an autonomic imbalance in the heart innervation (Rothrock, 2004).

Causes for bradycardia can be either intrinsic (e.g. cardiac abnormalities), or extrinsic (e.g. medication). During general anaesthesia children are at an increased risk of bradycardia in case of hypoxemia or hypervagotonia. Hypoxemia can be caused by administration of anaesthetics or other medication. Hypervagotonia can be evoked by oesophageal or nasal stimulation as a consequence of anaesthesia, for example in case of endotracheal intubation. However, surgery can also cause hypervagotonia by manipulation of the head or neck region, which is especially the case in otolaryngology. Among otolaryngology surgical procedures, adenotonsillectomy is a procedure likely to be responsible for direct stimulation of the vagal nerve. This stimulation is caused by placement of the mouth gag and the instruments used during the surgical procedure and the manipulation in the mouth and oropharynx. Together with placement of ventilation tubes, adenotonsillectomy is one of the most frequently performed types of surgery in children worldwide. 


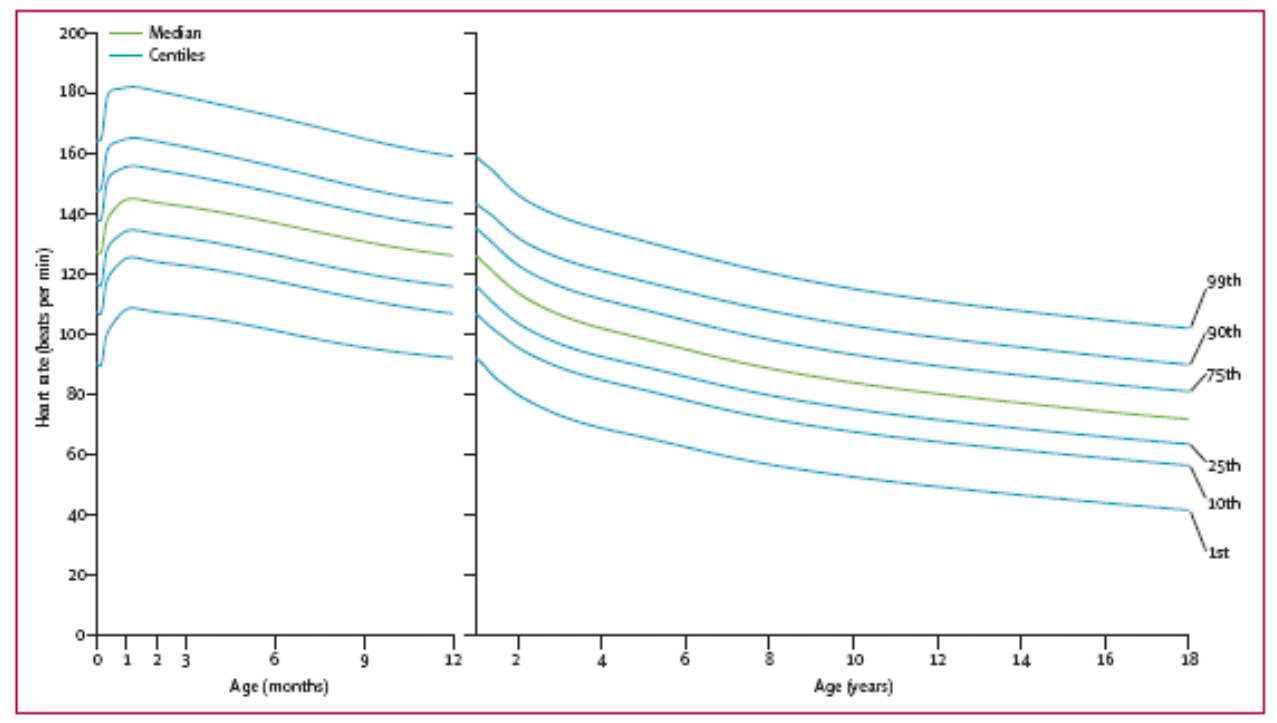

Fig. 1. Heart rate values in centiles from birth to age 18. (Fleming et al, 2011)

\subsection{Aetiology}

Bradycardia during general anaesthesia can have different causes, and depending on patient characteristics and conditions, the sequelae can be serious. Especially in children, bradycardia can lead to failure of cardiac output and may also lead to serious cardiac arrhythmias and even cardiac arrest. In a study performed by the Australian Patient Safety Foundation, the first 4000 incidents reported to the Australian Incident Monitoring Study (AIMS) were analysed for the incident bradycardia. A total of 265 reports describing bradycardia in both adults and children during anaesthesia were extracted and studied (Watterson et al., 2005). In general, bradycardia was associated with hypotension in $51 \%$ of cases, cardiac arrest in $25 \%$ of cases and hypertension in one case. In $22 \%$ of reports apparent desaturation or an abnormality of ventilation was described. The authors concluded that cardiopulmonary events causing bradycardia are more likely than other causes to be associated with cardiac arrest. The causes of bradycardia were drug events in $28 \%$ of cases, airway related events in $16 \%$, autonomic reflexes in $14 \%$, and regional anaesthesia in $9 \%$ of the cases. Most episodes of bradycardia occurred during surgery (61\%), whereas $20 \%$ was observed before and during induction.

In 43 of these 265 reports, bradycardia occurred in children under the age of 14 years. The distribution of ASA grading in children was similar to that of adults, but the haemodynamic profile was different for children as compared to adults. Whereas in adults airway and drug events together were responsible for $44 \%$ of causes, in children up to $75 \%$ of bradycardias were associated with airway and drug events. Airway events were the predominant cause of bradycardia in children (47\%). In $51 \%$ of children studied there was no abnormality of blood pressure, which was attributed to the high incidence of airway events, in which hypoxaemia was associated with rapid deterioration in heart rate. Hypotension was present in $21 \%$ of the cases, but cardiac arrest was described in $32 \%$ of the cases. Whereas a good 
outcome was reported in $63 \%$ of both adults and children, in only $48 \%$ of incidents concerning children a good outcome was reported. This might indicate that an incident during general anaesthesia with bradycardia in children has an important risk of poor outcome.

An epidemiologic study by Keenan and co-workers on bradycardia during anaesthesia concluded from data abstracted from almost 8,000 anaesthetic records of children 0-4 years of age that the frequency of bradycardia was $1.27 \%$ in the age group $0-1$ years of age. This was considerably less in the older age groups, that is $0.65 \%$ and $0.16 \%$ in the $3^{\text {rd }}$ and $4^{\text {th }}$ year of age, respectively (Keenan et al., 1994). Causes of bradycardia included disease or surgery in $35 \%$, inhalation anaesthetics in $35 \%$, and hypoxaemia in $22 \%$ of children. Hypotension was observed in $10 \%$ of patients, whereas asystole of ventricular fibrillation occurred in $10 \%$. All children underwent non-cardiac surgery and brdaycardia was defined as heart rate lower than 100 beats per minute. The study population was considerably younger than in the study described by Watterson. The authors concluded that bradycardia was more frequent in very young children aged 0-1 years undergoing anaesthesia, and that it was associated with substantial morbidity such as hypotension and asystole.

\subsection{Airway related}

The laryngeal reflex prevents foreign substances from entering into the lower airway and maintaining upper airway integrity. However, in some circumstances the laryngeal reflexes can induce cardiorespiratory events, that can even lead to life-threatening events such as apnea or even death. Gastroesophageal and pharyngolaryngeal refluxes are associated with both bradycardia and apnea, and may play a role in acute life threatening events (ALTE) or sudden infant death syndrome (SIDS). In airway management during general anaesthesia the laryngeal reflex can cause bradycardia by vagal stimulation and apnoea (Reix et al., 2007). In procedures especially during induction of anaesthesia, such as intubation, bradycardia and apnoea can be provoked. Other manoeuvres, like inserting a nasal feeding tube or head manipulation after endotracheal intubation, can induce bradycardia in a later phase of anaesthesia. In newborns and infants the upper airway sensitivity is even increased due to the immaturity of the chemo- and mechanoreceptors in the larynx. The innervation of the larynx is displayed in Figure 2.

In airway management during anaesthesia, the incidence of bradycardia is reported to be $0.5-4.2 \%$, and the risk is increased when children are younger (Keenan et al., 1994, Fastle and Roback, 2004; Gencorelli et al., 2010). In an analysis of bradycardia incidents during anaesthesia, $20 \%$ of bradycardia events occurred in the pre-induction or induction phase (Watterson et al. 2005). In a large study population of 1070 children aged 3-12 years who underwent rapid sequence induction for intubation, bradycardia was observed in 5 patients $(0.5 \%)$. Bradycardia was defined as a heart rate lower than 60 beats per minute. In the same study group, moderate hypoxemia with $\mathrm{SaO}_{2}$ of $80-89 \%$ was observed in 20 patients $(1.9 \%)$ and 18 patients $(1.7 \%)$ developed severe hypoxemia with $\mathrm{SaO}_{2}$ lower than $80 \%$. The risk for hypoxemia was increased when the weight was below $20 \mathrm{~kg}$ (Gencorelli et al., 2010). In another group of 163 children undergoing rapid sequence induction for intubation, the incidence of bradycardia was $4 \%$. The median age was 12 months (range 3 months to 19 years), which might explain the higher incidence of bradycardia. Definition of bradycardia was a heart rate falling two standard deviations below normal for age as described by the American Heart Association (Table 1). 


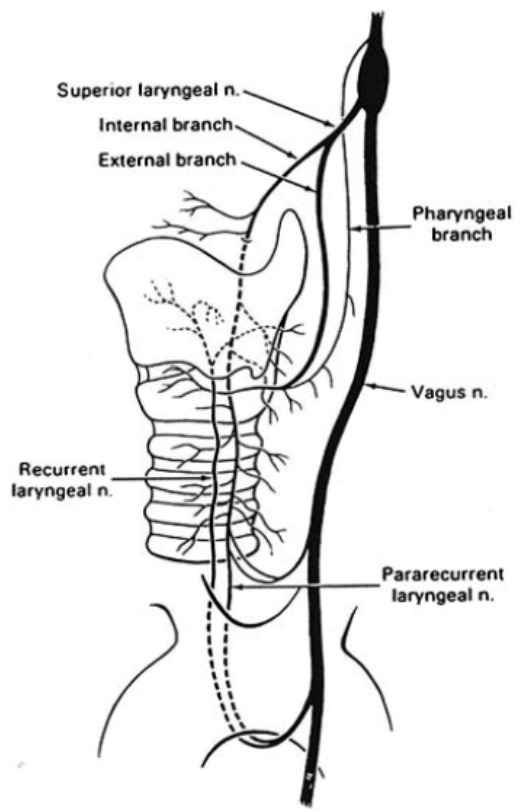

Fig. 2. Innervation of the larynx, reproduced from Reix et al, 2007

\begin{tabular}{|l|l|}
\hline Age & Heart Rate \\
\hline $0-3$ months & $85-205$ \\
\hline 3 months to 2 years & $100-190$ \\
\hline $2-10$ years & $60-140$ \\
\hline$>10$ years & $60-100$ \\
\hline
\end{tabular}

Table 1. The 95\% confidence interval for normal heart rates in children (American Heart Association).

Analysis of the children with bradycardia showed hypoxemia prior to the bradycardia in 4 out of 6 patients. Most of the patients were intubated for respiratory disease (45\%), trauma $(19 \%)$, or seizures $(12 \%)$. All bradycardia episodes resolved with ventilation or after endotracheal intubation (Fastle and Roback, 2004). In a series of 475 children (aged 1-22 years) who underwent operative intervention for post-tonsillectomy haemorrhage, bradycardia during rapid sequence induction was observed in 20 (4.2\%) of patients. Bradycardia was defined as a heart rate lower than 60 beats per minute, appearing in at least two consecutive recorded vital signs, 15 seconds apart. In total 9.9\% of the studied cohort had a moderate or severe hypoxemic event. Moderate hypoxemia was defined as $\mathrm{SaO}_{2}<$ $90 \%$, and severe hypoxemia was defined as $\mathrm{SaO}_{2}<80 \%$. All bradycardia events resolved without pharmacological intervention (Fields et al., 2010).

\subsection{Medication related}

Many drugs used in the operating theatre can cause bradycardia. Calcium-channel blockers and B-blockers are specifically used to slow heart rate. Also amiodarone has calcium channel 
and B-blocking properties. Most anaesthetics used during general anaesthesia have the potential of inducing bradycardia. In an extensive meta-analysis, propofol was associated with increased risk of bradycardia, also when compared to other anaesthetics (Tramèr et al., 1997), an odds ratio of 2.3 is thereby reported. Although it is difficult to compare the different trials, it seems clear that propofol carries an evident risk of bradycardia. The risk of death after bradycardia during propofol anaesthesia was 1.4/100.000. However, propofol is often administered together with opioids and muscle relaxants, which are also associated with bradycardia. By stimulation of the muscarinic receptors of the heart, suxamethonium (a depolarizing muscle relaxant) can cause bradycardia. Case reports on the occurrence of bradycardia or even asystole with the use of succinylcholine have been published (Delphin et al., 1987). However, incidence numbers are lacking. Also other non-depolarizing muscle relaxants and opioids like fentanyl or remifentanil have been associated with development of bradycardia in a meta-analysis of 85 randomised, controlled trials (Komatsu et al., 2007). Clonidine, an $\alpha$-2-receptoragonist which is frequently used in addition to local anaesthesia, can also elicit bradycardia (Pöpping et al., 2009). From the vapour anaesthetics, halothane has been associated with the most cardiovascular changes, including bradycardia especially in adenotonsillectomy (van Nouhuys, 1973; Slappendel \& Rutten, 1989). Data on bradycardia and the use of sevoflurane, isoflurane and desflurane is scarce. Thus, many drugs used in the perioperative period have been more or less associated with bradycardia. It is however difficult to elucidate which drugs contribute most to this risk, as randomized trials are lacking and most drugs are administered simultaneously.

\subsection{Premedication with atropine}

As discussed before, children that need endotracheal intubation commonly develop bradycardia. In literature there is discussion about the effect of premedication with atropine in children under the age of 5 . Some authors advise atropine as pretreatment in all children under 1 year of age receiving succinylcholine and all patient with profound bradycardia during intubation. As stated earlier, bradycardia during intubation is probably due to combined vagal response and hypoxia. During intubation the vagal nerve is activated and because the parasympathetic-sympathetic imbalance in young children, this reaction is more profound in children. This imbalance disappears at the age of one year (Rothrock and Pagane, 2005). By administrating atropine, or other anticholinergic medication, the incidence of bradycardia could decrease. Atropine inhibits the binding of acetylcholine on the muscarinereceptors, thereby diminishing the vagal response and bradycardia. On the other hand, atropine can induce dysrhythmias, such as tachycardia. It has some side-effects that could be unwanted, such as malignant hyperthermia, seizure and an increased risk of aspiration by relaxation of the lower oesophageal sphincter. In case of underdosing of atropine, there is a chance of provoking bradycardia. In case of overdosing, ventricular dysrhythmias and tachyarrhythmia may occur.

The review of Fleming and co-workers is a good overview of the evidence pro and contra the use of atropine. Most evidence for the use of atropine as a standard in all children under the age of 18 is from before 1990. Halothane and repeated succinylcholine was often used in that period. Therefore there was an increased risk for bradycardia. Nowadays, incidence of bradycardia is decreased because other anaesthetics showing less side-effects are used. Considering the disadvantage of atropine, it can be stated that standard premedication is not advised (Fleming et al., 2005). 


\subsection{Physical status}

Infants with a poor physical status have an increased risk for bradycardia. A higher ASA score is associated with more bradycardia, especially with an ASA score higher than 3. Infants with congenital diseases, especially heart disease may develop bradycardia easier and more prominent. Formally pre-mature infants have considerably more risk for apnoea and bradycardia. This can be associated with cardiac arrest and death. To reduce this risk, elective surgery should be postponed until after 55 weeks of post conceptual age. For explanation of ASA score, see Table 2.

\begin{tabular}{|l|l|}
\hline ASA score & \\
\hline 1 & A normal healthy patient \\
\hline 2 & A patient with mild systemic disease \\
\hline 3 & A patient with severe systemic disease \\
\hline 4 & A patient with severe systemic disease that is a constant threat to life \\
\hline 5 & A moribund patient who is not expected to survive without the operation \\
\hline 6 & $\begin{array}{l}\text { A declared brain-dead patient whose organs are being removed for donor } \\
\text { purposes }\end{array}$ \\
\hline
\end{tabular}

Table 2. ASA classification system according to the American Society of Anaesthesiologists.

Children with Down syndrome have an increased risk of developing bradycardia during anaesthesia. Up to $50 \%$ of them have congenital cardiac abnormalities. But irrespective of the presence or absence of congenital heart disease, bradycardia as well as hypotension during anaesthetic induction in children with Down syndrome $(n=567)$ occurred more frequently as compared to controls (Kraemer et al., 2010). Although patients with Down syndrome develop bradycardia at the same time after induction, the decrease in heart rate from baseline was greater in patients with Down syndrom as compared to healthy children (Bai et al., 2010).

The presence of obstructive sleep apnea-hyppopnea syndrome (OSAS) can influence the heart rate in children. Bradycardia is a common feature in children with OSAS during overnight sleep (Huang et al., 2008). Children woth OSAS undergoing adenotonsillectomy had more respiratory complications (Sanders et al., 2006).

\subsection{Age}

Cardiovascular and respiratory factors are the major causes of cardiopulmonary arrest in the pediatric population during anesthesia. Data from the American Society of Anesthesiologist Closed Claims Project showed that cardiopulmonary arrest during anesthesia in the pediatric population was different than in the adult population. In the pediatric population, cardiopulmonary arrest during anesthesia was commonly caused by respiratory events (inadequate ventilation with cyanosis and/or bradycardia proceding the cardiac arrest) and is more likely to result in mortality than in the adult cases. As known from the in 1994 founded Pediatric Perioperative Cardiac Arrest (POCA) registry anesthesia related cardiopulmonary arrest is fortunately an uncommon event, that is 1.4 per 10,000 . It must, however, be emphasized that although cardiac arrest is rare significant, bradyarrhythmias must be treated immediately to prevent an irreversible cardiac arrest which occurs in $26 \%$ and have a mortality rate of $72 \%$ (Morray, 2010). Special precaution measurement should be considered in patients less than 1 year with severe underlying or concurrent disease having 
emergency surgery as they are the most at risk for a fatal outcome. In patients who are ASA 1 or $2,64 \%$ of the cardiac arrests are medication-related arrests. In these patients conservative management includes removing or reducing the dose of drugs known to inhibit the sinus atrial node or removing the surgical stimulus (i.e oculocardia reflex). If this is not effective or possible, anticholinergics like atropine or sympathicomimetics (i.e. ephedrine, epinephrine, isoproterenol) must be considered. The risk of bradycardia and cardiovascular complications in children is inversely proportional to age.

\subsection{Temperature}

Lowering temperature is a risk for developing bradycardia, in children as well as in adults. In extreme cases of hypothermia (less than $32^{\circ} \mathrm{C}$ ), extreme bradycardia with a heart rate of less than 40 beats per minute may occur. In a case report concerning a child with an extreme bradycardia of 30 beats per minute at a temperature of $24.8^{\circ} \mathrm{C}$, no serious effects in neurological outcome were observed (Balagna et al., 1999). In adults hypothermia is often deliberately used in patients after cardiac arrest to protect their brain. These patients have a better neurological outcome. In these adults, bradycardia is often monitored. Usually there is no decreased myocardial contractility (Polderman and Herold, 2009).

\section{The incidence of bradycardia in children undergoing adenotonsillectomy}

\subsection{Incidence and surgical technique}

Adenotonsillectomy is one of the most frequently performed types of surgery in children worldwide. The surgical rate in United States and England is approximately 50-65 per 10,000, respectively. In the Netherlands the surgical rate in 1998 was 115, and was even higher in the decades before (Van den Akker et al., 2004). In the last decade, the incidence of adenotonsillectomy has decreased to a surgical rate of 110 per 10,000 in 2008 (Prismant, 2010). In The Netherlands, the most frequently used surgical technique for adenotonsillectomy is the guillotine technique as described by Sluder in 1911. One of the advantages of the guillotine technique as compared to traditional dissection is a shorter duration of surgery (Mulder et al., 1995). Moreover, several studies have shown that the guillotine technique is less painful (Homer et al., 2000). Finally, there is less blood loss during surgery, and the incidence of postoperative haemorrhage is lower (Wake et al., 1989; Ünlü et al., 1992; Scheenstra et al., 2007; Lowe et al., 2007). The guillotine technique can be performed intubated and nonintubated under inhalation anaesthesia. A nonintubated adenotonsillectomy can be performed either in supine of sitting position.

Whereas the traditional dissection technique for adenotonsillectomy is the dominant technique worldwide, in The Netherlands guillotine adenotonsillectomy is most frequently performed, and in the majority of patients the surgery is performed nonintubated under inhalation anaesthesia (Tjon Pian Gi et al., 2010). For several years, there has been discussion about the ideal anaesthesia technique for adenotonsillectomy, either intubated or nonintubated. Those in favor of the intubated technique, claim that the most important reason to use endotracheal intubation is that the airway is secured, thus allowing the administration of inhalation anaesthetics and/or oxygen. Moreover, intubation could decrease the incidence of aspiration of blood or tissue, for example of the adenoid or tonsils. However, there is no evidence whether intubation indeed decreases the risk of aspiration of, for example, blood. In the nonintubated child, the short duration of anaesthesia and the fact that no intravenous muscle relaxantia are used, may allow the child to recover more quickly 
and thus decrease the risk of aspiration of blood, since laryngeal reflexes will be earlier as compared to intubated patients due to the use of more anaesthetics. This, among others, may be in favor of performing adenotonsillectomy nonintubated under inhalation anaesthesia. As already mentioned, the duration of surgery is substantially shorter. Moreover, the amount of inhalated anaesthetics administered to the child is less as compared to children undergoing adenotonsillectomy intubated. Only inhalation anaesthetics (sevoflurane) are necessary, whereas for the intubated technique muscle relaxantia are required. In a Dutch study performed by Mulder, it was found that the incidence of postoperative fever and pain was lower in children undergoing adenotonsillectomy under inhalation anaesthesia and nonintubated as compared to those undergoing the adenotonsillectomy intubated (Mulder et al., 1995). An explanation for this observation could be that intubation through an infection upper airway (tonsils) might facilitate spread of microorganisms to the lower respiratory tract. Another explanation was that the children undergoing adenotonsillectomy nonintubated had better laryngeal and tracheal reflexes, thus allowing a more effective removal of aspirated fluids by coughing direct postoperatively.

\subsection{Hypoxemia and bradycardia in children undergoing adenotonsillectomy}

Cardiac arrhythmias as a consequence of bradycardia have been described in children undergoing adenotonsillectomy with inhalation anaesthesia (Van Nouhuys, 1973; Slappendel and Rutten, 1989). The inhalation anaesthetics used in these studies were nitrous oxide, halothane and trichloroethylene. Although nitrous oxide is still used nowadays, the used of trichloroethylene and halothane has been decreased significantly. The different types of inhalation anaesthetics, and the specific type of surgery may well contribute to the occurrence of bradycardia. Only few studies have compared different anaesthesia techniques, nonintubated versus intubated, and comparison of the supine versus sitting position. In a prospective, randomised trial three groups of patients were compared (Knape, 1988). The first group of patients $(n=42)$ underwent adenotonsillectomy with Sluder technique nonintubated, in a sitting position. In a second group of patients $(n=42)$, the adenotonsillectomy was performed intubated. The third group $(n=38)$ underwent circumcision nonintubated. Oxygen levels were registered using pletysmography. In this study, the pulse rate was not assessed. The incidence of hypoxemia was measured for each group. Hypoxemia was defined as $\mathrm{SaO}_{2}$ lower than $90 \%$ and severe hypoxemia as $\mathrm{SaO}_{2}$ lower than $75 \%$. Nitrous oxide was used as inhalation anaesthetic, together with halothane, for all patients including those undergoing adenotonsillectomy intubated. The number of episodes per 100 patients was calculated for hypoxemia. In the nonintubated group undergoing adenotonsillectomy in a sitting position, the number of hypoxemia episodes was 331 per 100 patients, which was significantly higher than the incidence of hypoxemia in the group undergoing adenotonsillectomy with intubation, 29 per 100 patients. The incidence of hypoxemia in the control group undergoing circumcision was 32 per 100 patients. Severe hypoxemia with $\mathrm{SaO}_{2}$ lower than $75 \%$ was only observed in the patients undergoing adenotonsillectomy in a sitting position and nonintubated. The incidence of severe hypoxemia was 117 per 100 patients. Hypoxemia occurred at the end of surgery and direct postoperatively in the nonintubated group undergoing adenotonsillectomy in a sitting position, whereas hypoxemia in the intubated group was seen after extubation. In the control group undergoing circumcision nonintubated hypoxemia was observed at the time the child got awake, indicating laryngospasm. In the study by van der Werff, a total of four 
groups were compared with different anaesthesia techniques (van der Werff et al., 1991). Children underwent adenotonsillectomy with Sluder technique nonintubated $(n=20)$, adenoidectomy $(n=20)$, adenotonsillectomy with Sluder technique nonintubated with placement of grommets $(n=20)$, or only placement of grommets $(n=20)$. All patients underwent surgery in a supine position. In none of the patient groups severe hypoxemia with $\mathrm{SaO}_{2}$ lower than $75 \%$ was observed. In the group of patients undergoing adenotonsillectomy with Sluder technique nonintubated with placement of grommets, the mean $\mathrm{SaO}_{2}$ was $94 \%$ versus $97 \%$ for the other groups. Wagemans performed continuous $\mathrm{SaO}_{2}$ registration and assessment of pulse rate in 37 children undergoing adenotonsillectomy or placement of grommets under inhalation anaesthesia (Wagemans et al., 1991). Adenotonsillectomy was performed nonintubated, in a sitting position. Both groups received nitrous oxide and halothane as inhalation anaesthetics. Hypoxemia was defined as $\mathrm{SaO}_{2}$ lower than $90 \%$ and bradycardia was defined as a heart frequency under 70 beats per minute. In the patients undergoing adenotonsillectomy, a mean $\mathrm{SaO}_{2}$ of $94.7 \%$ was found, as compared to a mean $\mathrm{SaO}_{2}$ of $96.5 \%$ in the patient group undergoing placements of grommets. This was not significantly different. In only one patient (5.3\%) undergoing adenotonsillectomy a single $\mathrm{SaO}_{2}$ lower than $90 \%$ was observed. The time of hypoxemia was 35 seconds and the lowest registration value of $\mathrm{SaO}_{2}$ was $74 \%$. Bradycardia was not observed in both groups. These findings were considerably different from those described by Knape, who found in $80 \%$ of patients hypoxemia with a $\mathrm{SaO}_{2}$ lower than $90 \%$. The authors concluded that the duration of surgery was increasingly shorter in their study population for adenotonsillectomy: 24 seconds versus 80 seconds in the patients studies by Knape. They concluded that the interaction between the anaesthesiologist and otolaryngologist was of great importance, resulting in a shorter duration of surgery. This leads to their conclusion that performing adenotonsillectomy under inhalation anaesthesia nonintubated in a sitting position, is a safe procedure. Based on these studies the Dutch Association of Otolaryngology and Head \& Neck Surgery, in cooperation with the Dutch Institute for Healthcare Improvement (CBO) published the practice guideline 'Adenoid and tonsil disorders in secondary care' in 2008 (CBO, 2008). In this practice guideline, the advice was given to perform adenotonsillectomy using guillotine technique according to Sluder in a supine position if nonintubated inhalation anaesthesia is given.

In a study recently performed by our departments, we retrospectively analysed the incidence of hypoxemia and bradycardia in children undergoing adenotonsillectomy (Kretzschmar et al., 2010). Analysis was performed on a total of 2963 children who underwent adenotonsillectomy nonintubated in a sitting position. Hypoxemia was defined as a $\mathrm{SaO}_{2}$ lower than $85 \%$ with a duration longer than 60 seconds. Incidental desaturation was defined as $\mathrm{SaO}_{2}$ lower than $90 \%$, with a duration shorter than 60 seconds. Bradycardia was defined as a heart frequency under 60 beats per minute, for longer than 30 seconds. Incidental bradycardia was defined as a heart frequency lower than 60 beats per minute for a duration shorter than 30 seconds. For both incidental desaturation and bradycardia, the incidence per 100 patients was calculated in order to compare our data with earlier studies described above. Sevoflurane was used as inhalation anaesthetic. Hypoxemia occurred in 132 patients $(4.5 \%)$ and the incidence of incidental desaturations $\left(\mathrm{SaO}_{2}\right.$ lower than $\left.90 \%\right)$ was 217 per 100 patients. In 1724 patients no incidental desaturations at all were seen. In 280 patients $(9.4 \%)$ bradycardia was observed. The incidence of incidental bradycardia, a heart frequency lower than 60 beats per second but shorter than 30 seconds, was 234 per 100 patients. In 2683 patients $(90.6 \%)$ bradycardia with a heart rate lower than 60 and a duration 
of more than 30 seconds did not occur. In 25 patients $(0.8 \%)$ bradycardia and hypoxemia both occurred. The bradycardia was registered at the same moment or directly after hypoxemia in 3 of these 25 patients. All episodes were reversible and in none of the patients peri-operative complications due to hypoxemia or bradycardia were observed.

\begin{tabular}{|l|l|l|l|}
\hline & No Hypoxemia & Hypoxemia & Total \\
\hline No Bradycardia & $2576(86.9 \%)$ & $107(3.6 \%)$ & $2683(90.6 \%)$ \\
\hline Bradycardia & $255(8.6 \%)$ & $25(0.8 \%)$ & $280(9.4 \%)$ \\
\hline Total & $2831(95.5 \%)$ & $132(4.5 \%)$ & $2963(100 \%)$ \\
\hline
\end{tabular}

Table 3. Incidence of hypoxemia and bradycardia in patients undergoing adenotonsillectomy. Hypoxemia was defined as a $\mathrm{SaO}_{2}$ lower than $85 \%$ with a duration longer than 60 seconds. Bradycardia was defined as a heart frequency under 60 beats per minute, for longer than 30 seconds.

Different explanations for the occurrence of bradycardia can be given. Bradycardia as a direct consequence of hypoxemia is one of these, and can indicate severe problems during anesthesia. This was only observed in 3 of the patients $(0.001 \%)$, and was reversible in all of them. It seems that the specific type of surgery is more likely to cause the bradycardia. Due to the placement of the mouth gag and guillotine procedure with manipulation of the tissue of the pharyngeal wall it is likely that the vagus nerve is stimulated leading to a reflex of lowering the heart rate.

We concluded that bradycardia and hypoxemia both occur during adenotonsillectomy nonintubated in a sitting position. Both bradycardia and hypoxemia have shown to be reversible and do not lead to perioperative complications. The incidence of bradycardia directly during or after an episode of hypoxemia is extremely rare, in our study the incidence was $0.001 \%$. However, bradycardia does occur relatively often, that is in $9.5 \%$ of patients. One of the most important explanations is the specific kind of surgery, where stimulation of the vagal nerve leads to bradycardia.

\section{Discussion}

Cardiac output is determined by the product of heart rate and left ventricular stroke volume. Bradycardia may result in an insufficient rate to sustain cardiac output and hence oxygen delivery to tissue beds. This is particularly so in the case of young children in whom cardiac output is more affected by changes in heart rate than stroke volume. A prompt appropriate response to bradycardia under anaesthesia is important as some causes are rare and/or obscure and homeostatic mechanisms may be impaired by anaesthetic agents. Hamilton and co-workers suggest in a recent meta-analysis that a preemptive targeted approach to the management of hemodynamics in the perioperative period may reduce morbidity and mortality for high-risk surgical patients (Hamilton et al., 2011). Flick et al reported that postoperative cardiac arrest occurred most often in children with congenital heart disease as a result of factors not related to anesthesia. While cardiac surgery accounted for only $5 \%$ of all procedures, $87.5 \%$ of all arrests occurred in patients with congenital heart disease, usually during cardiac surgery as a result of failure to wean from cardiopulmonary bypass. Anesthesia factors were related in only $7.5 \%$ of all arrests, with an incidence of 0.65 per 10,000 anesthetics. Only six anesthesia-related arrests occurred in noncardiac cases during the 17-yr study period (Flick et al., 2007). 


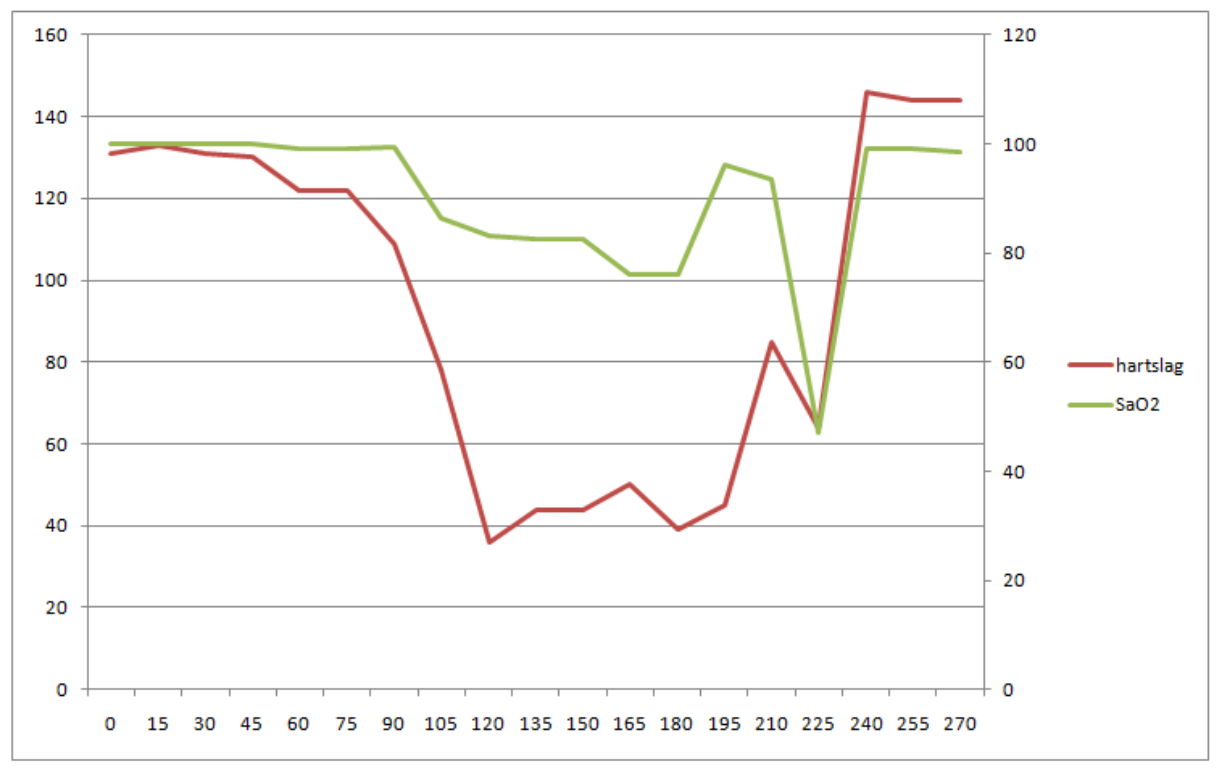

Fig. 3. Registration results of $\mathrm{SaO}_{2}$ (green line, right axis, $\mathrm{SaO}_{2}$ in \%) and heart rate (red line, left axis, in beats per minute) as measured in time (horizontal-axis, in seconds) during inhalation anaesthesia in a 6-years old child undergoing adenotonsillectomy in sitting position.

During adenotonsillectomy under inhalation anaesthesia, bradycardia and hypoxemia both occur. In our study on children undergoing adenotonsillectomy in a sitting position nonintubated, both bradycardia and hypoxemia have shown to be reversible and do not lead to perioperative complications. The incidence of bradycardia directly during or after an episode of hypoxemia was extremely rare $(0.001 \%)$. However, bradycardia does occur relatively often, in $9.5 \%$ of patients undergoing adenotonsillectomy in a sitting position nonintubated. An explanation might be a combination of study population, relatively young children, as well as the anaesthetics used, and the specific type of surgery leading to stimulation of the vagal nerve. Further research is necessary to compare different anesthesia techniques for adenotonsillectomy, with and without intubation.

\section{Conclusion}

Both bradycardia and hypoxemia occur relatively often during adenotonsillectomy, performed nonintubated in a sitting position under inhalation anaesthesia. The incidence of bradycardia in these children is $9.5 \%$. Both bradycardia and hypoxemia are reversible and do not lead to perioperative complications. The incidence of bradycardia directly during or after an episode of hypoxemia is extremely rare. In general, in the pediatric population cardiovascular and respiratory factors are the major causes of cardiopulmonary arrest during anesthesia. The major causes of anesthesia-related cardiac arrest in the pediatric population are hypovolemia, preoperative anemia, pharmacological toxicity, hypoventilation and airway obstruction. Cardiopulmonary arrest during anesthesia in the 
pediatric population is different as compared to the adult population. In children, cardiopulmonary arrest during anesthesia is commonly caused by respiratory events and is more likely to result in mortality than in the adults. Anesthesia related cardiopulmonary arrest is fortunately an uncommon event, but it must be emphasized that significant bradyarrhythmias must be treated immediately to prevent an irreversible cardiac arrest. Special precaution measurement should be considered in patients less than 1 year with severe underlying or concurrent disease having emergency surgery as they are the most at risk for a fatal outcome. Finally, it must be clear that children should be cared for in facilities with adequate skilled medical and nursing staff and appropriately sized equipment.

\section{References}

Bai W., Voepel-Lewis, T., Malviya S. (2010) Hemodynamic changes in children with Down syndrome during and following inhalation induction of anesthesia with sevoflurane. Journal of Clinical Anesthesia, Vol 22, pp. 592-597

Balagna, R., Abbo, D., Ferrero, F., Valori, A., Peruzzi, L. (1999) Accidental hypothermia in a child. Paediatric Anaesthesia, Vol. 9: 342-244

CBO Kwaliteitsinstituut voor de gezondheidszorg (2008) Richtlijn Ziekten van Adenoïd en Tonsillen in de Tweede lijn. Utrecht: http://www.cbo.nl/thema/Richtlijnen/Overzicht-richtlijnen/KNO

Fastle, R.K. and Roback, M.G. (2004) Pediatric rapid sequence intubation. Incidence of reflex bradycardia and effects of pretreatment with atropine. Pediatric Emergency Care, Vol. 20 (10), pp. 651-655

Field, R.G., Gencorelli F.J., Litman, R.S. (2010) Anesthetic management of the pediatric bleeding tonsil. Pediatric Anaesthesia, Vol. 20, pp. 982-986

Fleming, B., McCollough, M., Henderson, S.O. (2005) Myth: atropine should be administered before succinylcholine for neonatal and pediatric intubation. Can J Emerg Med, Vol. 7 (2), pp. 114-117

Flick R.P., Sprung J., Harrison T.E., Gleich S.J., Schroeder D.R., Hanson A.C., Buenvenida S.L., Warner D.O. (2007) Perioperative cardiac arrests in children between 1988 and 2005 at a tertiary referral center: A study of 92,881 patients. Anesthesiology, Vol. 106, pp. 226-237

Gencorelli F.J., Fields, R.G., Litman, R.S. (2010) Complications during rapid sequence induction of general anaesthesia in children: a benchmark study. Pediatric Anaesthesia, Vol. 20, pp. 421-424

Hamilton, M.A., Cecconi, M., Rhodes, A. (2011) A Systematic Review and Meta-Analysis on the Use of Preemptive Hemodynamic Intervention to Improve Postoperative Outcomes in Moderate and High-Risk Surgical Patients. Anesth \& Analg, Vol. 112(6), pp. 1259-1521

Homer, J.J., Williams, B.T., Semple, P., Swanepoel, A. en Knight, L.C. (2000) Tonsillectomy by guillotine is less painful than by dissection. Int J Pediatr Otorhinolaryngol, Vol 52, pp. $25-29$

Huang, Z., Liu, D., Zhong, J., Chen, Q., Zhou, L., Sun, C., Wang, J. (2008) Lin Chung Er Bi Yan Hou Jing Wai Ke Za Zhi, Vol 22 (21), pp. 984-986

Keenan, R.L., Shapiro, J.H., Kane, F.R., Simpson, P.M. (1994) Bradycardia during Anesthesia in Infants. An Epidemiologic Study. Anesthesiology, Vol 80, pp. 976-982 
Kalkman, C.J., Peelen, L., Moons, K.G., Veenhuizen, M., Bruens, M., Sinnema, G., De Jong, T.P. (2009) Behavior and Development in Children and Age at the Time of First Anaesthetic Exposure. Anesthesiology, Vol 110, pp. 805-812

Knape, J.T.A. (1989) Het verloop van de arteriële zuurstofsaturatie bij twee anesthesietechnieken voor (adeno)tonsillectomie bij kinderen. Ned Tijdschr Geneeskd, Vol 132, pp. 919-922

Komatsu, R., Turan, A.M., Orhan-Sungur, M., McGuire, J., Radke, O.C., Apfel, C.C. (2007) Remifentanyl for general anaesthesia: a systematic review. Anesthesiology, Vol. 62 (12), pp. 1266-1280

Kraemer, F.W., Stricker, P.A., Gumaney, H.G., McClung, H., Meador, M.R., Sussman, E., Burgess, B.J., Ciampa, B., Mendelsohn, J., Rehman, M.A., Watcha, M.F. (2010) Bradycardia During Induction of Anaesthesia with Sevoflurane in Children with Down Syndrome. Anesth Analg, Vol. 111, pp. 1259-1263

Kretzschmar, M.J., Siccama, I., Houweling, P.L., Quak, J.J., Colnot, D.R. (2010) Hypoxemia and bradycardia in children during adenotonsillectomy without intubation. Ned Tijdschr Geneesk, Vol. 154, pp. 1715-1719

Lowe, D., van der Meulen, J., Cromwell, D., Lewsey, J., Copley, L., Browne, J., Yung, M., Brown, P. (2007) Key messages from the National Tonsillectomy Audit. Laryngoscope, Vol 117, pp. 717-724

Morray, J.P. (2010) Cardiac arrest in anesthetized children: recent advances and challenges for future. Pediatric Anesthesia, doi:10.1111/j.1460-9592.2010.03440.x

Mulder, J.J.S., Mönnink, J.P., De Grood, P.M.R.M. (1995) Adenotonsillectomie volgens Sluder: met of zonder endotracheale intubatie? Ned Tijdschr Geneeskd, Vol 139, pp. 2730-2732

O'Connell T. Update in paediatric cardiopulmonary resuscitation. In: Keneally J, ed. Australasian anaesthesia. Melbourne: ANZCA, 1994:27-37

Polderman, K.H., Herold, I. (2009) Therapeutic hypothermia and controlled normothermia in the intensive care unit: practical considerations, side effects, and cooling methods. Crit Care Med, Vol. 37 (3), pp. 1101-1120

Pöpping, D.M., Alia, N., Marret, E., Wenk, M., Tramèr, M.R. (2009) Clonidine as an adjuvant to local anaesthetics for peripheral nerve and plexus blocks: a meta-analysis of randomized trials. Anesthesiology, Vol. 111(2), pp. 406-415

Prismant (2010), Informatie-expertise, ziekenhuisstatistieken, verrichtingen. Available from: www.prismant.nl

Scheenstra, R.J., Hilgevoord, A.A.J. en Van Rijn, P.M. (2007) Ernstige nabloeding na klassieke (adeno)tonsillectomie: zeldzaam en meestal op de dag van de ingreep. Ned Tijdschr Geneeskd, Vol 151, pp. 598-601

Reix, P., St-Hilaire, M., Praud, J-P. (2007) Laryngeal sensitivity in the neonatal period: from bench to bedside. Pediatric Pulmonology, Vol. 42, pp. 674-682

Rothrock, S.G. and Pagane, J. (2005) Letter to the Editors. Pediatric Emergency Medicine, Vol. 21 (9), pp. 637-638

Sanders, J.C., King, M., Mitchell, M.A., Kelly, J.P. (2006) Perioperative complications of adenotonsillectomy in children with obstructive sleep apnea syndrome. Anesth Analg, Vol 103 (5), pp. 1115-1121

Slappendel, R. \& Rutten, J.M.J. (1989) Hartritmestoornissen tijdens adenotomie en adenotonsillectomie. Ned Tijdschr Anesthesiol, Vol2, pp. 11-13 
Tjon Pian Gi, R., Bliek, V., Borgstein, J. (2010) The Sluder method in the Netherlands and the incidence of postoperative haemorrhage in a pediatric hospital. Int $J$ Ped Otorhinolaryngol, Vol 74, pp. 56-59

Tramèr, M.R., Moore, R.A., McQuay, H.J.M. (1997) Propofol and bradycardia: causation, frequency and severity. Brit J Anaesthesia, Vol. 78, pp. 642-651

Ünlü, Y, Tekalan, S.A, Cemiloglu, R., Ketenci, I., Kutluhan, A. (1992) Guillotine and Dissection Tonsillectomy in Children. J Laryngol Otol, Vol. 106, pp. 817-820

Van den Akker, E.H., Hoes, A.W., Burton, M.J., Schilder, A.G.M. (2004) Large International Differences in (adeno)tonsillectomy rates. Clin Otolarynol, Vol. 29, pp. 161-164

Van der Meulen, J. (2004) Tonsillectomy technique as a risk factor for postoperative haemorrhage. Lancet, Vol 364, pp. 697-702

Van Nouhuys, F. (1973) Afwijkingen in het elektrocardiogram tijdens adenotonsillectomie onder narcose. Ned Tijdschr Geneeskd, Vol 117, pp. 137-141

Wagemans, M.F.M., van Dijk, B., Bakker, N.C., Ten Voorde, B.J., Faes, Th.J.C., Zuurmond, W.W.A., van der Werff, D.B.M., Scheffer, G.J. (1991). Continue $\mathrm{SaO}_{2}$-meting en ECG-registratie onder inhalatieanesthesie voor adenotonsillectomie bij kinderen in zittende houding. Ned Tijdschr Anesth, Vol 4, pp. 61-61

Wake, M. \& Glossop, P. (1989). Guillotine and dissection tonsillectomy compared. J Laryngol Otol, Vol. 103, pp. 588-591

Watterson, L.M., Morris, R.W., Westhorpe, R.N., Williamson, J.A. (2005) Crisis management during anaesthesia: bradycardia. Qual Saf Health Care, Vol. 14: e7 


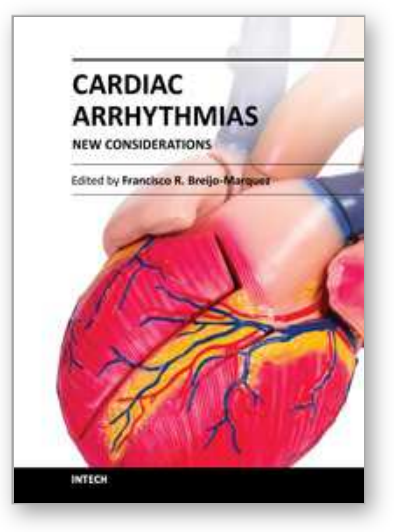

\author{
Cardiac Arrhythmias - New Considerations \\ Edited by Prof. Francisco R. Breijo-Marquez
}

ISBN 978-953-51-0126-0

Hard cover, 534 pages

Publisher InTech

Published online 29, February, 2012

Published in print edition February, 2012

The most intimate mechanisms of cardiac arrhythmias are still quite unknown to scientists. Genetic studies on ionic alterations, the electrocardiographic features of cardiac rhythm and an arsenal of diagnostic tests have done more in the last five years than in all the history of cardiology. Similarly, therapy to prevent or cure such diseases is growing rapidly day by day. In this book the reader will be able to see with brighter light some of these intimate mechanisms of production, as well as cutting-edge therapies to date. Genetic studies, electrophysiological and electrocardiographyc features, ion channel alterations, heart diseases still unknown , and even the relationship between the psychic sphere and the heart have been exposed in this book. It deserves to be read!

\title{
How to reference
}

In order to correctly reference this scholarly work, feel free to copy and paste the following:

Judith A. Lens, Jeroen Hermanides, Peter L. Houweling, Jasper J. Quak and David R. Colnot (2012). Bradycardia in Children During General Anaesthesia, Cardiac Arrhythmias - New Considerations, Prof. Francisco R. Breijo-Marquez (Ed.), ISBN: 978-953-51-0126-0, InTech, Available from: http://www.intechopen.com/books/cardiac-arrhythmias-new-considerations/bradycardia-in-children-duringgeneral-anaesthesia

\section{INTECH}

open science | open minds

\author{
InTech Europe \\ University Campus STeP Ri \\ Slavka Krautzeka 83/A \\ 51000 Rijeka, Croatia \\ Phone: +385 (51) 770447 \\ Fax: +385 (51) 686166 \\ www.intechopen.com
}

\author{
InTech China \\ Unit 405, Office Block, Hotel Equatorial Shanghai \\ No.65, Yan An Road (West), Shanghai, 200040, China \\ 中国上海市延安西路65号上海国际贵都大饭店办公楼 405 单元 \\ Phone: +86-21-62489820 \\ Fax: $+86-21-62489821$
}


(C) 2012 The Author(s). Licensee IntechOpen. This is an open access article distributed under the terms of the Creative Commons Attribution 3.0 License, which permits unrestricted use, distribution, and reproduction in any medium, provided the original work is properly cited. 